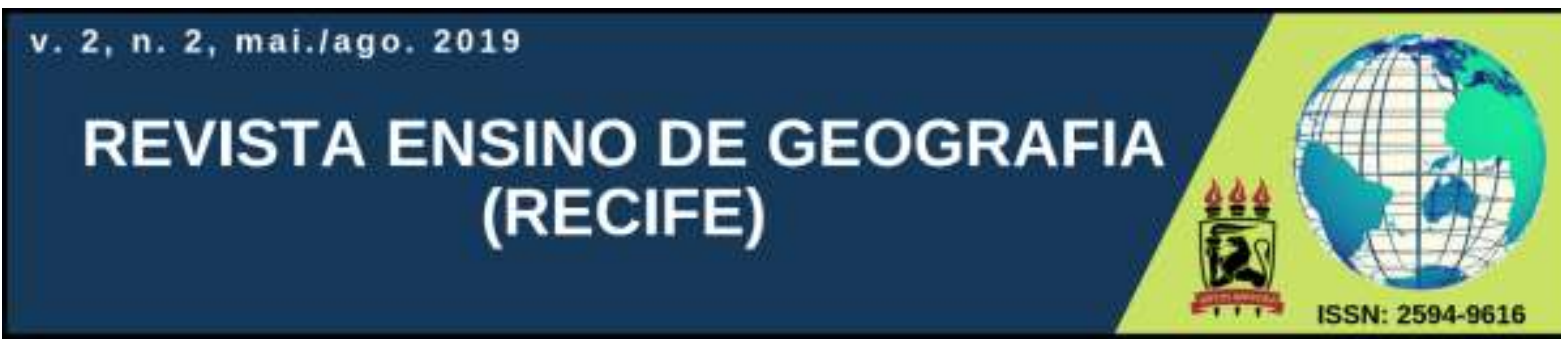

\title{
O CURRÍCULO EM MOVIMENTO ENQUANTO POLÍTICA PÚBLICA E O ENSINO DE GEOGRAFIA VOLTADO PARA A CIDADANIA E A SUSTENTABILIDADE
}

\author{
Maria Solange Melo de Sousa \\ Universidade de Brasília - UNB \\ sollangemello@uol.com.br \\ ORCID Id: $\underline{\text { http://orcid.org/0000-0002-4362-7845 }}$ \\ Marília Luíza Peluso \\ Universidade de Brasília - UNB \\ peluso177@gmail.com \\ ORCID Id: http://orcid.org/0000-0002-9630-5014
}

Artigo recebido em 26/04/2019 e aceito em 03/10/2019

\begin{abstract}
RESUMO
$\mathrm{O}$ artigo discutirá a importância de ações pedagógicas que trabalhem os conhecimentos geográficos de forma interdisciplinar e explorando os temas transversais de cidadania, diversidade e sustentabilidade. A discussão será permeada pela análise de documentos como o Currículo em Movimento das Escolas Públicas, o Projeto Político Pedagógico Carlos Mota, ambos da Secretaria de Estado de Educação do Distrito Federal, o Projeto Político Pedagógico de uma escola pública, localizada em Taguatinga, Região Administrativa do Distrito Federal, o Centro Educacional 04; pesquisa bibliográfica de autores que tratam de temas diversos relacionados às políticas públicas, às práticas pedagógicas, às questões sociais e aos conhecimentos geográficos; e, na apresentação de uma ação pedagógica realizada em uma escola pública, para fundamentar as argumentações desenvolvidas ao longo do artigo. A discussão tem por objetivo entender que a autonomia na construção do conhecimento geográfico é possível por meio de ações proativas que valorizem o desenvolvimento da aprendizagem em uma abordagem interdisciplinar. $\mathrm{O}$ resultado da investigação mostra que a ação pedagógica realizada na escola, corroborou na análise dos temas discutidos e que a formação cidadã plena perpassa pela compreensão dos valores éticos, de respeito à diversidade e na promoção de uma sociedade sustentável.
\end{abstract}

Palavras-chaves: Cidadania; Currículo em Movimento; Diversidade; Geografia; Sustentabilidade.

\section{THE CURRICULUM IN MOTION AS A PUBLIC POLICY AND THE TEACHING OF GEOGRAPHY FOCUSED ON CITIZENSHIP AND SUSTAINABILITY}

\begin{abstract}
The article will discuss the importance of pedagogical actions that work the geographic knowledge in an interdisciplinary way and exploring the transversal themes of citizenship, diversity and sustainability. The discussion will be permeated by the analysis of documents such as the Public School's Moving Curriculum, the Carlos Mota Pedagogical Political Project, both from the Federal Department of State of Education, the Pedagogical Political Project of a public school, located in Taguatinga, Administrative Region. from the Federal District, the Educational Center 04; bibliographic research of authors who deal with various themes related to public policies, pedagogical practices, social issues and geographic knowledge; and, in the presentation of a
\end{abstract}


pedagogical action carried out in a public school, to support the arguments developed throughout the article. The discussion aims to understand that autonomy in the construction of geographic knowledge is possible through proactive actions that value the development of learning in an interdisciplinary approach. The result of the research shows that the pedagogical action carried out at school corroborated the analysis of the themes discussed and that full citizen formation goes through the understanding of ethical values, respect for diversity and the promotion of a sustainable society.

Keywords: Citizenship; Diversity; Geography; Moving Curriculum; Sustainability

\section{INTRODUÇÃO}

A educação é considerada um dos caminhos mais eficazes para o desenvolvimento de um país. A partir dessa premissa, para que a educação cumpra sua função social e favoreça a formação de cidadãos que contribuam para o desenvolvimento, há a necessidade de mudar o contexto da educação para além do viés econômico que domina as políticas educacionais no Brasil. O pensamento neoliberal traz consigo paradigmas no que diz respeito à participação do Estado na condução da economia brasileira e, isso inclui a forma com que se vê a educação, que adquire um perfil mais mercadológico. Logo, discutir projetos educacionais exitosos é essencial para corroborar com os avanços na educação, uma vez que a qualidade na formação dos estudantes é importante para qualquer nação dinamizar o seu desenvolvimento.

A partir da percepção empírica de um país marcado por desigualdades sociais, pode-se considerar que o Brasil é um país em que as políticas públicas não alcançam toda a sociedade. $\mathrm{O}$ desenvolvimento econômico ocorrido a partir da segunda metade do século $\mathrm{XX}$, não favoreceu para a superação dos graves contrastes sociais, com isso, as desigualdades promovem situações de vulnerabilidades diversas, dentre elas, a qualidade da educação. Para Nascimento e Botelho (2016, p. 01) "tais desigualdades não têm, na maioria dos casos, uma origem única e este fato demanda que a formulação das políticas públicas esteja atenta a multicausalidade dos problemas sociais aos quais se procura enfrentar através das ações estipuladas pelas políticas".

Assim como os contrastes sociais, outro tema que necessita ser analisado por interferir na educação é a diversidade, que é marcante e envolve questões étnicas, culturais e desigualdades socioeconômicas no espaço territorial brasileiro, no qual aspectos multifacetados e complexos são vivenciados. A heterogeneidade e a diversidade cultural são concebidas em ambientes de encontros entre pessoas de várias culturas, histórias e identidades como, por exemplo, nas escolas e os professores têm grande importância para mediar as relações entre os atores inseridos na comunidade escolar. É possível considerar que, provavelmente, a heterogeneidade contribua para fortalecer as relações sociais e propiciar o convívio de pessoas plurais, no sentido cultural e socioeconômico. 
A reflexão sobre educação, heterogeneidade e diversidade não dizem respeito apenas ao reconhecimento do outro como diferente. Significa pensar a relação entre o eu e o outro, para que o indivíduo não se transforme em um ser essencialmente materialista e egocêntrico por sentir-se intrínseco ao sistema econômico estabelecido, no caso, Capitalismo. Em seu artigo "A era do humanismo está terminando" Mbembe (2017, grifo nosso) infere que "os valores estão distorcidos", para o autor "a difamação de virtudes como o cuidado, a compaixão e a generosidade alia-se a crença, principalmente entre os pobres, de que ganhar é o que importa e, em última instância, a coisa certa”.

A escola neste processo de interação propicia a reflexão e pressupõe uma análise crítica no sentido da transformação social, principalmente pautada na superação das injustiças sociais. É nesse contexto de desigualdades e diversidade que o Currículo em Movimento das Escolas Públicas do Distrito Federal será analisado em uma perspectiva de política pública e como proposta de contribuir para a formação do estudante como ser social, a partir da compreensão de que o currículo teve na sua construção um caráter democrático por envolver vários atores ligados ao cotidiano do processo pedagógico.

O artigo está estruturado em cinco partes: procedimentos metodológicos; a educação como pilar do desenvolvimento; o Currículo em Movimento enquanto política pública; Currículo em Movimento, práticas pedagógicas e resultados e considerações finais.

Os procedimentos metodológicos descrevem que o artigo foi construído a partir de pesquisas documentais e bibliográficas e da análise de uma ação pedagógica realizada em uma escola pública. Na segunda parte o artigo traz a discussão pautada na educação em uma abordagem mais humanista e argumenta que a escola não pode ter como pressuposto a formação de cidadãos que priorizem o "ter" em detrimento ao "ser". Para atingir este objetivo é preciso dialogar com outros agentes da educação que formam a comunidade escolar, trazendo a família e sua cultura de origem para junto do cotidiano da sala de aula, para assim então pautar a construção do saber e valorizar a própria história, reconhecendo-se como um ser social.

Quando a discussão envolve a questão do currículo como política pública, o texto apresenta um breve histórico da construção do documento, apresentado o caráter democrático no processo de elaboração e como o Currículo em Movimento utiliza a interdisciplinaridade para nortear a construção das aprendizagens em uma perspectiva de integração de conteúdo. Em seu caderno de pressupostos teóricos mostra que: “O princípio da interdisciplinaridade estimula o diálogo entre os conhecimentos científicos, pedagógicos e experiências, criando 
possibilidades de relações em diferentes conhecimentos é áreas [...]” (DISTRITO FEDERAL, 2012, p. 68).

Na quarta parte, o artigo trata dos conteúdos geográficos e discute os resultados da ação pedagógica. Quanto aos conteúdos geográficos, o texto mostra a importância deles na aprendizagem e apresenta possibilidades de promover práticas pedagógicas interdisciplinares e de forma transversal por meios de temas ligados à cidadania, à diversidade e à sustentabilidade e tendo como pilar de sua condução o currículo da Secretaria de Estado de Educação do Distrito Federal. Na discussão dos resultados, o artigo analisa as contribuições alcançadas com o desenvolvimento da ação pedagógica e, em função dos resultados positivos, o projeto foi incorporado como tema do componente curricular PD (Projeto Diversificado) na instituição de ensino, no caso, o Centro Educacional 04 de Taguatinga.

Nas considerações finais faz-se uma análise das discussões desenvolvidas no texto em relação à importância do Currículo em Movimento enquanto política pública e como ele favorece para o bom desempenho e a qualidade da educação pública no Distrito Federal. Também se analisa as potencialidades de práticas pedagógicas exitosas no ensino de Geografia a partir da cidadania, da diversidade e da sustentabilidade em uma abordagem interdisciplinar e transversal.

\section{PROCEDIMENTOS METODOLÓGICOS}

O artigo é uma análise documental do Currículo em Movimento da Educação Básica do Distrito Federal - no artigo ele será tratado apenas como Currículo em Movimento -, do Projeto Político Pedagógico da Instituição e do Projeto Político Pedagógico - Carlos Mota, da Secretaria de Estado do Distrito Federal. Para fundamentação teórica utilizou-se de pesquisa bibliográfica de autores que tratam de temas diversos relacionados às políticas públicas, às questões de desigualdades sociais e as práticas pedagógicas no ensino de Geografia. Por fim, apresentará a ação pedagógica desenvolvida em uma escola pública do Distrito Federal, com a intenção mostrar a aplicação efetiva das orientações contidas no Currículo em Movimento.

A partir da análise documental e de leituras diversas, o artigo discorreu a respeito da educação no contexto do desenvolvimento de uma nação; da importância do currículo, enquanto política pública nas práticas pedagógicas cotidianas; na formação plena do estudante e na construção dos conceitos geográficos; discutiu-se a relevância de uma ação pedagógica para a aprendizagem dos conhecimentos geográficos, a interação entre os pares no ambiente escolar, 
o envolvimento dos diversos segmentos da comunidade escolar para que a instituição seja um espaço propício para o desenvolvimento das relações sociais e que favoreça o respeito à cidadania, a diversidade e a sustentabilidade.

O artigo mostra a importância do currículo no cotidiano de uma escola quando a equipe gestora e o corpo docente desenvolvem práticas pedagógicas inovadoras explorando as potencialidades do documento, por meio de ações em uma dimensão interdisciplinar. A ação pedagógica que será apresentada no texto, foi realizada em uma escola pública do Distrito Federal, localizada na Região Administrativa de Taguatinga, o Centro Educacional 04.

\section{A EDUCAÇÃO COMO PILAR DO DESENVOLVIMENTO}

Muitas das nações se desenvolvem e prosperam por meio de investimento e valorização da educação. Há necessidade de promover mudanças substanciais na educação básica, na educação profissional, na graduação e na pós-graduação brasileira. Apesar dos investimentos financeiros serem essenciais, não é apenas eles que irão resolver o problema.

Mas como se produzir um pensamento próprio que não seja através da formação de cidadãos críticos e capacitados? O artigo propõe discutir como a elaboração de um currículo, enquanto política pública, pode contribuir para a formação plena do cidadão por meio de um ensino inovador, interdisciplinar e crítico e sua contribuição para o planejamento de práticas pedagógicas nas aulas de Geografia. Como é possível planejar políticas públicas para o desenvolvimento tendo como foco a educação? É preciso estimular os estudantes da educação básica a adquirir conhecimentos por meio da aprendizagem no âmbito local e baseando-se em experiências cotidianas, trilhadas pelo ensino de Geografia. Os planejamentos dos governos precisam investir no potencial técnico-científico para trilhar rumo a um desenvolvimento sustentável em um contexto de globalização mundial. Em 2009, o Jornal Folha de São Paulo online publicou no caderno Publifolha, um artigo que faz parte da coletânea de uma série de textos publicados pelo Geógrafo Milton Santos, no período entre 1981 até a sua morte, em 2001. No texto "Por uma globalização mais humana", Santos (2009, s/n) argumenta que: "O mundo parece agora, girar sem destino. É a chamada globalização perversa. Ela está sendo tanto mais perversa porque enormes possibilidades oferecidas pelas conquistas científicas e técnicas não estão sendo adequadamente utilizadas". 
As enormes possibilidades descritas por Santos (2009) podem ser justamente alcançar o desenvolvimento sustentável e que seja acessível a todos. O Brasil precisa compreender essa realidade, caso contrário, continuará sendo um país do futuro, mas em que o futuro é incerto. Assim, o sucesso de uma política pública exige que os atores envolvidos no processo acreditem em suas potencialidades. Lascoumes e Galês (2012, p. 67), consideram que a "implementação de uma política pública" e algo que precisa ser pensado: "Analisar a implementação significa interessar-se pela forma com que um programa público é apropriado e não apenas pela forma como ele foi concebido e estruturado [...]".

A educação enquanto política pública recebe críticas de vários segmentos da sociedade, porque ela não avança e seus resultados não colaboram para o desenvolvimento do país. Em relação à dimensão de uma política pública:

A análise dos fracassos ou limites dos programas públicos vai progressivamente evidenciar as fragilidades do modelo top down (de cima para baixo) e das abordagens estado-centradas. Ela demonstrará que, por equívoco, vinculamos política pública a um programa diretivo naturalmente dotado de autoridade e legitimidade (LASCOUMES E GALÊS, 2012, p. 68).

No Distrito Federal há tentativas de promover discussões relacionadas à educação pública de forma mais participativa, cujo exemplo é a Gestão Democrática e a construção do Currículo em Movimento. No primeiro, a proposta é ter o envolvimento de toda a comunidade escolar na gestão das escolas, por meio de eleições dos gestores e do Conselho escolar, constituído por todos os segmentos da comunidade escolar: professores, assistentes da educação, estudantes e pais. Na gestão democrática, a administração da escola é conduzida pelo diretor e pelo Conselho Escolar; a comunidade escolar participa da construção do Projeto Político Pedagógico (PPP) da instituição, por isso, ela permite o envolvimento da comunidade escolar no processo pedagógico a possibilidade de participar da reflexão, da discussão e da condução do trabalho pedagógico, com o objetivo de alcançar uma educação de qualidade. Em relação ao Currículo, ele representa uma grande conquista para os atores envolvidos no processo pedagógico, ele foi elaborado com a participação de gestores, supervisores, coordenadores e professores. 


\section{O CURRÍCULO EM MOVIMENTO ENQUANTO POLÍTICA PÚBLICA}

As políticas públicas precisam criar dinâmicas que favoreçam a resolução da complexidade dos problemas públicos em uma perspectiva democrática, isto é, que alcance os atores da sociedade civil que necessitem de fato dessas políticas e, mais uma vez, um desses temas a ser discutido é a educação, um direito humano básico do cidadão. O Distrito Federal, dentro das Unidades da Federação, tem um desempenho significativo em relação à qualidade no ensino da educação básica. No entanto, apresenta elevados índices de reprovação e abandono escolar. Na tentativa de superar as fragilidades que a educação do Distrito Federal enfrenta a Secretaria de Estado de Educação, no ano de 2011, deu início à organização de grupos de estudos com a participação de professores da rede pública para a elaboração de um novo modelo de currículo em que “[...] Procura romper as barreiras sociais, políticas, econômicas e culturais que segregam unidades escolares e distorcem as possibilidades de aprendizagens dos estudantes" (DISTRITO FEDERAL, 2012, p.4).

A discussão em torno do currículo desperta posicionamentos muitas vezes contraditórios por parte de especialistas e docentes como, por exemplo, a análise de Mello (2014) na qual considera a vertente do currículo centrada no conhecimento ou a vertente centrada no aluno. A primeira dá importância ao legado científico, cultural e artístico do passado, a segunda atribui ao conhecimento, um poder emancipador. Em uma terceira alternativa, o currículo deve ser centrado "na aprendizagem e no resultado, entendido como aquilo que o aluno deve saber e fazer" (MELLO, 2014, p. 2). Diante disso, percebe-se que o tema currículo necessita ser discutido porque ele interfere diretamente na qualidade de ensino.

O caderno de Pressupostos teóricos do Currículo em Movimento, assim descreve as discussões coletivas em relação ao currículo nas plenárias, realizadas a partir do ano de 2011, durante a construção do currículo das escolas públicas do distrito Federal:

[...] este é realmente um campo de disputas, de relações de poder, de tensões e conflitos, de defesa de interesses diversos, as vezes antagônicos, descartando qualquer pretensão desta secretaria em apresentar um currículo ideal, enquadrado perfeitamente numa única teoria e implementado rigorosamente numa perspectiva científicoracional (CURRÍCULO EM MOVIMENTO, 2012, P. 22).

A partir de toda a discussão acerca do currículo, o importante é compreender que ele não pode ser tratado como um fim em si mesmo, caracterizado pela prática docente em que o 
professor continua escravo do livro didático como instrumento norteador dos conteúdos trabalhados em sala de aula.

O Currículo em Movimento, tratado no artigo, refere-se ao currículo das escolas públicas do Distrito Federal. Ele é constituído por oito cadernos assim organizados: Pressupostos teóricos; Educação infantil; Ensino fundamental - anos iniciais; Ensino fundamental - anos finais; Ensino Médio; Educação profissional e a distância; Educação de jovens e adultos e Educação especial. Na sua concepção, era preciso superar a ideia de que currículo escolar é a prescrição de conteúdo. O projeto de construção de um novo currículo para as escolas públicas do Distrito Federal foi inovador e de vanguarda, uma vez que ele foi construído em etapas e envolveu diversos segmentos que constitui a comunidade escolar.

Em 2010, o currículo experimental foi apresentado aos gestores, coordenadores e docentes; em 2011, organizou-se grupos de trabalho, formado por professores e coordenadores para analisar o documento; no ano de 2012 o novo currículo estava pronto para a sua validação. Nessa etapa, que aconteceu no ano de 2013, grupos de trabalho foram organizados - de acordo com a área de conhecimento. A Secretaria de Estado de Educação do Distrito Federal promoveu cursos de capacitação para os professores trabalharem com o novo currículo.

O Currículo se baseia em quatro eixos estruturantes: princípios da cidadania, da diversidade, da aprendizagem e da sustentabilidade. A prática pedagógica na concepção de integração entre a teoria e a prática, permite que o estudante se identifique enquanto ser social que respeita a sua comunidade e as pessoas que a compõe, valorizando assim a sua realidade de espaço físico e a adoção de uma postura de tolerância e respeito ao próximo. Dentro desse contexto, o documento trabalha os eixos estruturantes por meio da reorganização de tempos e espaços escolares em busca de uma práxis mais eficaz do processo pedagógico.

Trazer para a discussão autores que dialoguem em uma perspectiva de transversalidade dos temas relacionados à cidadania, diversidade, aprendizagem e sustentabilidade, corroboram para ampliar a dimensão de se compreender a importância de tais princípios para o avanço na qualidade do ensino público. Para Cruz e Daroit (2017, p. 2), a transversalidade é uma categoria que repercute de forma significativa na contemporaneidade tanto em estudos de gestão de políticas públicas, quanto em "arenas povoadas por sujeitos que tecem a ação pública". O Currículo em Movimento representa uma dessas ações públicas, uma vez que foi construído de forma coletiva e democrática com a participação de atores diretamente envolvidos na dinâmica da educação pública. 


\section{CURRÍCULO EM MOVIMENTO, PRÁTICAS PEDAGÓGICAS E RESULTADOS}

O Projeto Político Pedagógico - Carlos Mota (2011), da Secretaria de Estado de Educação do Distrito Federal propõe uma educação comprometida com a formação integral do educando e a sustentabilidade humana como princípio das políticas públicas. Mas, para que isso se concretize há a necessidade de a escola criar possibilidades para que o estudante tenha conhecimento de seus direitos e de seus deveres, que ele seja capaz de se conscientizar de sua importância como ser social ativo. Para tanto, o Currículo em Movimento (2012) propõe práticas pedagógicas que enfatizem a participação ativa do estudante em seu processo educacional, oferecendo-lhe a chance de produzir significados a partir de uma íntima conexão entre o objeto de ensino e a vida. A partir desta perspectiva, faz-se necessário que a atuação do professor possibilite ao estudante utilizar a pesquisa científica como processo de produção de conhecimento, prática revolucionária que instiga o papel do aluno como protagonista no processo de ensino-aprendizagem.

Foi a partir da concepção da participação ativa do aluno e da importância de valorizar a pesquisa científica na construção do conhecimento, que a atividade foi pensada. A atividade explorou formas diversas de linguagem - escrita, oral, visual e corporal, e os conceitos geográficos, além de outros conceitos ligados às diversas áreas de conhecimento; valorizou-se a pesquisa científica e promoveu-se o sentimento de pertencimento do estudante com a escola. Esse sentimento de pertencimento desperta o gosto pela aprendizagem por promover a integração de atividades lúdicas e, referindo-se Freire (1996, p. 59), "Ensinar exige respeito à autonomia do ser do educando”. A prática pedagógica também favoreceu a realização de trabalhos baseados na transversalidade dos temas de cidadania, diversidade e sustentabilidade.

O projeto teve como objetivo entender que a formação cidadã plena permeia pela compreensão dos valores éticos e pela construção de uma sociedade sustentável. A metodologia para a realização da ação pedagógica foi desenvolvida por etapas. A princípio, a equipe docente promoveu uma palestra de sensibilização a respeito da importância atitudes focadas na cidadania, na diversidade e na sustentabilidade. Por meio de trabalhos em grupos, os alunos trabalharam com os conceitos de cidadania, diversidade, ética e sustentabilidade; pesquisaram os artigos $5^{\circ}$ e $6^{\circ}$ da Constituição Federal para construir os conceitos de direito e dever; estudaram os artigos da Constituição que tratam da saúde, da educação, da família, da criança, do adolescente e do meio ambiente, contemplando à análise da formação cidadã; analisaram leis e códigos de relevância social visando a comparação entre o institucional e o real. 
Em uma outra etapa do projeto, foi proposto aos estudantes que promovessem atitudes e práticas com foco na cidadania, na diversidade e na sustentabilidade, junto à comunidade escolar. A culminância do projeto foi realizada com a exposição de cartazes, painéis, fotos e apresentações artísticas relacionadas ao que foi pesquisado. Por fim, os estudantes produzem textos para relatar as experiências vivenciadas com a realização do projeto.

A Geografia trabalha de forma interdisciplinar com outros componentes curriculares e pode ser coautora na ruptura de paradigmas em meio a uma realidade social, marcada por mudanças latentes e aceleradas. Portanto, a temática do projeto está diretamente relacionada aos conhecimentos geográficos. Para Cavalcanti:

[...] Entende-se que a Geografia é uma leitura, uma perspectiva da realidade. Afirmase, então que o objetivo do ensino de Geografia é o de contribuir para o desenvolvimento do pensamento espacial do aluno de modo que ele, com a maior autonomia possível, possa pensar e agir sobre o mundo considerando a espacialidade das coisas nas coisas [...] (2017, p. 18).

Para o trabalho em sala de aula que vislumbre a construção da cidadania plena em que os jovens respeitem o seu próximo, a diversidade e o meio em que vivem, o trabalho precisa ser sensível às questões sociais e ambientais e que seja coautora da sustentabilidade humana. É papel da escola, sensibilizar os estudantes quanto à importância de uma sociedade que não seja alicerçada apenas em princípios capitalistas e focada em valores subjetivos. Em seu caderno do Ensino Médio, o Currículo em Movimento (2012, p. 17) infere que "Entender esses jovens significa superar uma noção homogeneizante e naturalizada, passando a percebê-los como sujeitos com valores, comportamento, visões de mundo, interesses e necessidades singulares".

A proposta pedagógica apresentada advém de vivências cotidianas relacionadas a adversidades e seus entraves no espaço de ensino aprendizagem. Para tanto, percebeu-se a necessidade da realização de práticas pedagógicas com foco na superação. Os alunos de escola pública devem ter a possibilidade de ser um elemento ativo, que procura compreender o mundo que o cerca, e que busca resolver as interrogações que esse mundo provoca. Assim a proposta é que os estudantes, por meio da pesquisa científica, desenvolvam princípios de emancipação baseados em uma educação cidadã e sustentável.

Em seu caderno dos pressupostos teóricos, o Currículo em Movimento (2012, p. 53) argumenta que "A organização política e social baseada na cidadania é um avanço importante para a inclusão de minorias nas políticas sociais" e, nesse contexto: 
A cidadania é uma ideia fundamentada em uma ordem jurídico-político, ou seja, o cidadão é membro de um determinado Estado e seus direitos ficam vinculados a decisões políticas. Por isso, os direitos de cidadania são variáveis em função de diferentes países e culturas e determinados por diversos momentos históricos (DISTRITO FEDERAL, 2012, p. 50).

A Geografia enquanto ciência humana tem a possibilidade de se apropriar do estudo da cidadania para desenvolver aprendizagens diversas de forma contextualizada que traga ao estudante a condição de compreender o seu papel como cidadão na mudança de paradigmas do meio em que está inserido. A prática pedagógica na concepção de integração entre a teoria e a prática, permitirá que o estudante se identifique enquanto ser social que respeita sua comunidade e as pessoas que a compõe, valorizando assim a sua realidade de espaço físico e a adoção de uma postura de tolerância, Mas é preciso também ampliar o seu foco de atitudes. No que se refere à compreensão do lugar vivido, é preciso formular conceitos do que se pretende estudar, avançar nas escalas de categorias analíticas geográficas, relacionar e compartilhar experiências vividas. Segundo Cavalcanti:

\begin{abstract}
Essas reflexões interessam ao professor de Geografia justamente porque cabe a ele ajudar o aluno na construção de um ponto de vista geográfico, de um olhar geográfico, ainda que elementar, pois não se trata de um olhar de especialista, de geógrafo, mas de cidadão e de sua vida cotidiana. Os cidadãos necessitam desses conhecimentos para vivenciar sua realidade imediata, mas também os requerem para compartilhar outras realidades, nas diversas escalas e relações do mundo globalizado (2017, p. 19).
\end{abstract}

Estudar a sustentabilidade é entender que o nosso planeta necessita urgentemente rever os seus conceitos no que diz respeito ao desenvolvimento, economia e qualidade de vida. Buscar a sustentabilidade é uma prática cidadã, que quer o melhor para si e para o seu próximo, logo ter uma concepção cidadã é ter também uma visão sustentável. O Currículo em Movimento, em seu caderno de pressupostos teóricos $(2012$, p.61), explica que "o conceito de desenvolvimento sustentável conduz ao raciocínio de um desenvolvimento que una a sociedade, o meio ambiente e a economia de forma equilibrada." e cita a ideia de Sachs (2004, p. 118): "devemos nos esforçar por desenhar uma estratégia de desenvolvimento que seja ambientalmente sustentável, economicamente sustentada e socialmente includente [...]”. Quando o estudante desenvolve uma atitude cidadã, ele também deve ter uma concepção de mundo sustentável, compreender qual o planeta que temos e qual o planeta que queremos.

Ao analisar o meio em que vive, a partir de uma análise crítica, o estudante perceberá como a comunidade se relaciona com o meio ambiente, qual o tratamento dado ao local pelo poder público, quais são as necessidades urgentes que o local reivindica. Mas o entendimento

\begin{tabular}{lll}
\hline Melo de Sousa e Peluso, 2019 & 39
\end{tabular}


de sustentabilidade vai muito além da relação homem/meio ambiente, pois quando se propõe a educação para a sustentabilidade temos por objetivo, a formação do estudante de forma integrada. A proposta da Secretaria de Estado de Educação do Distrito Federal (DISTRITO FEDERAL 2012, p. 58) é "oportunizar a professores e estudantes a construção de uma sociedade igualitária que atenda às necessidades do presente e conserve recursos naturais para as gerações futuras”. Para a eficácia da orientação, o Currículo em Movimento (2012, p. 58) apresenta subtemas da educação para a sustentabilidade, que foram trabalhadas na ação pedagógica da escola: "produção e consumo consciente; qualidade de vida; alimentação saudável; economia solidária; agroecologia; ativismo social; cidadania planetária; ética global, valorização da diversidade".

No Ensino Médio, o componente curricular de Geografia possui uma carga horária de duas aulas semanais e, assim, para trabalhar com essa prática pedagógica, a Instituição de ensino precisou buscar suporte no componente curricular PD (Projeto Diversificado), realizando um trabalho interdisciplinar para que as atividades fossem planejadas e executadas com qualidade. A integração curricular atende a proposta da Educação Básica da Secretaria de Educação do Distrito Federal, em que:

\begin{abstract}
As propostas curriculares integradas devem favorecer a descoberta de condicionantes sociais, culturais, econômicas e políticas dos conhecimentos existentes na sociedade possíveis a partir da conversão das salas de aula em espaços de construção e aperfeiçoamento de conteúdos culturais, habilidades, procedimentos e valores, num processo de reflexão. Os educadores que concebem o currículo nessa perspectiva o fazem com base em objetos educacionais que se pautam na busca da integração das diferentes áreas do conhecimento e experiências, com vistas à compreensão crítica e reflexiva da realidade (SANTOMÉ, 1998, p. 27).
\end{abstract}

Dentro dessa temática, os temas propostos e voltados ao contexto de uma educação para a sustentabilidade puderam ser explorados; os estudantes os relacionaram com a sua vivência e as atividades desenvolvidas possibilitaram a construção de conceitos de forma crítica e reflexiva.

Os resultados da ação pedagógica, desenvolvida nas aulas de Geografia, e em parceria com outros componentes curriculares, de forma interdisciplinar, fez-se sentir no cotidiano da instituição a diminuição de ocorrência de brigas entre alunos, atos de vandalismo, pichações e práticas de bullying. Com o sentimento de identidade e de pertencimento do estudante com a escola, na medida do possível, as relações interpessoais passaram a ser pautadas no respeito e 
na tolerância, a escola tornou-se mais limpa e sem pichações, a área verde mais apreciada e preservada pelos estudantes.

Quanto ao contexto pedagógico, a metodologia favoreceu aos estudantes uma postura proativa, uma vez que eles tiveram a possibilidade de participar de atividades que envolveram a sua vivência e o seu cotidiano; eles foram protagonistas na construção da aprendizagem, por meio de pesquisas e tiveram a oportunidade de mostrar o conhecimento adquirido realizando apresentações culturais, produções de textos e exposições de trabalho.

\section{CONSIDERAÇÕES FINAIS}

A discussão foi conduzida na perspectiva de compreender o alcance das políticas públicas, tendo como referência o Currículo em Movimento, que favoreçam a diminuição dos contrastes sociais e possibilitem ações em favor da cidadania uma vez que ele possibilita a concepção de mundo em um viés de eixos referentes à cidadania, à diversidade, à aprendizagem e à sustentabilidade. A perspectiva de uma aprendizagem interdisciplinar e com temas transversais proporciona reflexões e vivências acerca do respeito e tolerância às diferenças, o repúdio aos preconceitos e discriminações de qualquer ordem, o saber analisar e atuar nestas situações e de injustiças sociais e, enfim, uma formação pautada em valores morais e éticos.

A partir da construção de práticas pedagógicas centradas no estudante, dando a ele o acesso a conceitos necessários que o torne um cidadão crítico e consciente, favorece o alcance de resultados positivos no que diz respeito às questões pedagógicas, além da queda nos índices de evasão e reprovação. É preciso estabelecer uma relação de identidade do aluno com a escola. Assim, é pertinente se apoiar nas reflexões de Piaget (1974) como referência na análise de que a autonomia no respeito às leis e às regras, estabelecidas no Regimento Interno da Instituição, são opções que o sujeito faz na sua convivência social, pela autodeterminação.

A ação pedagógica apresentada mostra uma alternativa de superação que não é baseada em fórmulas tradicionais, mas sim no pensamento de que é possível transformar situações de instabilidade em perspectivas sociais positivas, tendo como suporte o respeito recíproco e a consciência de que o estudante traz para o ambiente escolar seus saberes, suas experiências e seus conceitos cotidianos e necessita que tudo isso seja trabalhado com base na teoria e na metodologia.

As ações proporcionadas aos estudantes do Centro Educacional 04 são possíveis quando os professores têm autonomia para construir e conduzir práticas pedagógicas inovadoras e o 
Currículo em Movimento da Secretaria de Educação do Distrito Federal, devido ao perfil democrático pelo qual ele foi pensado e elaborado, dá aos professores e as escolas esta possibilidade.

\section{REFERÊNCIAS}

BOTELHO, Denise; NASCIMENTO, Wanderson Flor do. Celebração móvel: políticas públicas, transversalidade e interseccionalidade de gênero e raça. In: SANTOS, Debora Silva; GARCIA-FILICE, Renísia Cristina; RODRIGUES, Ruth Meyre Mota. A transversalidade de gênero e raça nas políticas públicas: limites e possibilidades. Brasília, 2016.

CRUZ, Fernanda Natasha Bravo; DAROIT, Doriana. Dos nexos efêmeros ao fazer estado: ensaio sobre transversalidade em conferências nacionais de políticas públicas. NAU Social, v. 8, n. $15,2017.20$ Disponível http://www.periodicos.adm.ufba.br/index.php/rs/article/view/681/497. Acesso em 25 out 2018.

DISTRITO FEDERAL. Secretaria de Estado de Educação: Currículo em Movimento da Educação Básica - Ensino Médio, Departamento de Pedagogia, 2012.

Secretaria de Estado de Educação: Currículo em Movimento da Educação

Básica - Pressupostos teóricos, Departamento de Pedagogia, 2012.

Secretaria de Estado de Educação: Projeto Político Pedagógico do Centro Educacional 04 de Taguatinga, 2016.

Secretaria de Estado de Educação: Projeto Político Pedagógico das Escolas Públicas do DF - Carlos Mota, 2011.

CAVALCANTI, Lana de Souza. Ensino de Geografia e demandas contemporâneas: práticas e formação docentes. In: ALVES, Adriana Oliveira e KHAOULE, Ana Maria kavacs (orgs). A Geografia no cenário das políticas públicas educacionais. Goiânia: C\&A Alfa \& Comunicação, 2017. p. 18-19

FREIRE, Paulo. Pedagogia da Autonomia. 36a edição - São Paulo: Paz e Terra, 1996.

LASCOUMES, Pierre; LE GALÊS, Patrick. Sociologia da Ação Pública: A entrada chave das políticas públicas. EDUFAL, Maceió, 2012

MBEMBE, Achille. A era do humanismo está terminando. Opera Mundi. De, v. 10, 2017 Disponível em: http://www.ihu.unisinos.br/564255-achille-mbembe-a-era-do-humanismoesta-terminando. Acesso em 18 set 2018.

MELLO, Guiomar Namo de. Currículo da Educação Básica no Brasil: Concepções e políticas, set 2014. Microsolft Word - 20140926@ historicoCurricularBrasil_final.doc. Disponível em: movimentopelabase.org.br/wp-content/imploads/2015/09/guiomar_pesquisa.pdf. Acesso em: 28 ago 2019. 
PIAGET, Jean e GRÉCO, Pierre. Aprendizagem e Conhecimento. Rio de Janeiro: Freitas Bastos, 1974.

SACHS, I. Desenvolvimento includente, sustentável, sustentado. Rio de Janeiro: Garamond, Universitária/SEBRAE. 2004. 151 p.

SANTOMÉ, J. T. Globalização e interdisciplinaridade: o currículo integrado. Porto Alegre: Artes Médicas, 1998.

SANTOS, Milton. O país distorcido. In: Por uma Globalização mais Humana. Folha online, São Paulo, 15 ago de 2019. Caderno Publifolha. Disponível em: www1.folha.uol.com.br/folha/publifolha/ult10037u351805.shtml. Acesso em 22 abr 2019. 